\title{
Effects of the PPAR $\gamma$ agonist GW1929 on muscle wasting in tumour-bearing mice
}

\author{
RODRIGO MOORE-CARRASCO ${ }^{1,2}$, MAITE FIGUERAS ${ }^{1}$, ELISABET AMETLLER ${ }^{1}$, \\ FRANCISCO J. LÓPEZ-SORIANO ${ }^{1}$, JOSEP M. ARGILÉS ${ }^{1}$ and SÍLVIA BUSQUETS ${ }^{1}$ \\ ${ }^{1}$ Departament de Bioquímica i Biologia Molecular, Universitat de Barcelona, Barcelona, Spain; \\ ${ }^{2}$ Departamento de Bioquímica Clínica e Inmunohematología, Universidad de Talca, Talca, Chile
}

Received March 2, 2007; Accepted July 27, 2007

\begin{abstract}
Administration of the PPAR $\gamma$ agonist GW1929 (10 $\mathrm{mg} / \mathrm{kg}$ body weight) results in amelioration of muscle loss in tumour-bearing mice experimental cachexia. The effect of the agonist, which seems to be specific for white muscle extensor digitorum longus (EDL), is accompanied by an increase in the levels of the transcription factor MyoD and also the GLUT-4 glucose transporter. In addition, the effects of GW1929 on skeletal muscle are direct since incubation of isolated rat skeletal muscles in its presence results in a decreased rate of protein degradation. Collectively, the results presented suggest a potential clinical application - possibly in combination with other anabolic strategies - of GW1929 in restoring muscle waste during cancer cachexia.
\end{abstract}

\section{Introduction}

Muscle wasting is a common feature in many pathological states including infection and cancer (1). Muscle wasting, the main trend of cachexia, is responsible for the death of at least $30 \%$ of cancer patients (2). The mechanisms involved in muscle wasting during cancer have previously been described by our group (3), and include an activation of skeletal muscle protein degradation $(4,5)$ together with apoptosis (6) and activation of uncoupling proteins (UCPs) (7).

Peroxisome proliferator-activated receptors (PPARs) are transcription factors belonging to the superfamily of nuclear receptors. Three isoforms $(\alpha, \delta$ and $\gamma$ ) have been described (8). They act on DNA response elements as heterodimers with the nuclear retinoic acid receptor. Their natural activating ligands are fatty acids and lipid-derived substrates. PPAR-

Correspondence to: Dr Sílvia Busquets, Cancer Research Group, Departament de Bioquímica i Biologia Molecular, Facultat de Biologia, Universitat de Barcelona, Diagonal 645, 08028 Barcelona, Spain

E-mail: silviabusquets@ub.edu

Key words: PPAR $\gamma$, muscle wasting, cancer, MyoD, glucose transport, GLUT-4 gamma (PPAR $\gamma)$ is expressed in adipose tissue, lower intestine, cells involved in immunity and other tissues (9). Activation of PPAR $\gamma$ induces the differentiation of preadipocytes into adipocytes and stimulates triglyceride storage (10).

A limited amount of information is available on the effects of PPAR $\gamma$ in skeletal muscle. Recent data from our laboratory indicate that the expression of PPAR $\gamma$ in skeletal muscles of tumour-bearing rats is significantly increased, suggesting that this transcription factor may have a role in muscle wasting. Bearing this in mind, the aim of the present investigation was to analyse the effects of GW1929 (an agonist of PPAR $\gamma$ ) on skeletal muscle in tumour-bearing animals submitted to cachexia.

\section{Materials and methods}

Animals. Male C57BL6 mice (Interfauna, Barcelona, Spain), of 5 weeks of age, were used in the experiment. The animals were maintained at $22 \pm 2^{\circ} \mathrm{C}$ with a regular light-dark cycle (light on from 08:00 a.m. to 08:00 p.m.) and had free access to food and water. The food intake was measured daily. All animal manipulations were made in accordance with the European Community guidelines for the use of laboratory animals.

Tumour inoculation and treatment. Mice were divided into two groups, namely controls and tumour hosts. The latter received an intramuscular innoculum of $0.5 \times 10^{6}$ Lewis Lung carcinoma cells in the leg obtained from exponential tumours. Both tumour and non-tumour-bearing animals were subdivided into two groups according to treatment. The treated groups were injected intraperitoneally with a daily dose of GW1929 (10 mg/kg body weight) dissolved in PEG 400 (carrier) during 5 consecutive days. The non-treated groups received an equivalent injection of the carrier. On day 13 after tumour transplantation, the animals were weighed and anesthetized with an i.p. injection of ketamine/xylazine mixture $(3: 1)$ (Imalgene ${ }^{\circledR}$ and Rompun ${ }^{\circledR}$, respectively). The tumour was harvested from the leg and its weight evaluated. Tissues were rapidly excised, weighed and frozen in liquid nitrogen.

Muscle preparations and incubations. The dissection, isolation and incubation of the extensor digitorum longus 
Table I. Food intake, body, tumour and muscle weights in tumour-bearing mice.

\begin{tabular}{|c|c|c|c|c|}
\hline & $\begin{array}{l}\mathrm{C} \\
(4)\end{array}$ & $\begin{array}{c}C+\text { GW1929 } \\
\text { (4) }\end{array}$ & $\begin{array}{l}\mathrm{T} \\
(6)\end{array}$ & $\begin{array}{c}\mathrm{T}+\mathrm{GW} 1929 \\
\text { (6) }\end{array}$ \\
\hline FBW-IBW & $1.8 \pm 0.5$ & $1.9 \pm 0.5$ & $-2.8 \pm 0.4^{\mathrm{a}}$ & $-2.2 \pm 0.3^{\mathrm{a}}$ \\
\hline Food intake & $34.5 \pm 3$ & $36.5 \pm 3$ & $30 \pm 4$ & $33 \pm 4$ \\
\hline \multicolumn{5}{|c|}{ Muscle weights } \\
\hline GSN & $562 \pm 25$ & $563 \pm 14$ & $389 \pm 20^{\mathrm{a}}$ & $382 \pm 20^{a}$ \\
\hline Soleus & $23 \pm 1$ & $30 \pm 5$ & $19 \pm 2$ & $21 \pm 2$ \\
\hline EDL & $32 \pm 3$ & $33 \pm 4$ & $22 \pm 2^{b}$ & $28 \pm 2^{c}$ \\
\hline Tibialis & $178 \pm 12$ & $181 \pm 6$ & $118 \pm 6^{\mathrm{a}}$ & $116 \pm 4^{\mathrm{a}}$ \\
\hline \multicolumn{5}{|c|}{ Tumour weight } \\
\hline & & & $2.8 \pm 0.3$ & $3.4 \pm 0.1$ \\
\hline \multicolumn{5}{|c|}{$\begin{array}{l}\text { For further details, see Materials and methods section. The results are mean values } \pm \text { SEM for the number of animals indicated in parentheses } \\
\text { Food intake ( } \mathrm{g} \text { ) is referred to the ingestion for each rat during the period of the experiment prior to sacrifice (13 days). Tissue weights ar } \\
\text { expressed as mg/ } 100 \mathrm{~g} \text { of initial body weight. Tumour weight is expressed in grams }(\mathrm{g}) \text {. GW } 1929 \text { was given for } 5 \text { days intraperitoneal }(1 \\
\mathrm{mg} / \mathrm{kg} \text { body weight). C, control; GW } 1929 \text {, treated animals; } \mathrm{T} \text {, tumour-bearing animals; IBW, initial body weight; FBW, final body weigh } \\
\text { without tumour; GSN, gastrocnemius; EDL, extensor digitorum longus. Values that are significantly different by the Student's t-test from th } \\
\text { non-tumour-bearing animals groups are indicated by }{ }^{a} \mathrm{p}<0.001,{ }^{b} \mathrm{p}<0.01 \text {. Values that are significantly different by the Student's t-test from th } \\
\text { non-treated animals are indicated by }{ }^{\mathrm{c}} \mathrm{p}<0.05 \text {. }\end{array}$} \\
\hline
\end{tabular}

(EDL) muscles was carried in rats out under ketamine/xylazine mixture anesthesia as previously described (11). The muscles were preincubated for $60 \mathrm{~min}$ : $30 \mathrm{~min}$ in Krebs-Henseleit buffer and $30 \mathrm{~min}$ in supplemented medium containing $10^{-4} \mathrm{M}$ GW1929 (Sigma Chemical Co., St. Louis, MO, USA) or none, and then incubated for $120 \mathrm{~min}$ in fresh supplemented medium. Total protein degradation by the isolated muscles was calculated as the rate of tyrosine released in the last two hours of incubation into the medium in the presence of $0.5 \mathrm{mM}$ cycloheximide in order to block the reincorporation of tyrosine into tissue protein. Tyrosine was measured fluorimetrically as previously described (12).

Western blotting. For Western blots, protein extracts from tissues were prepared in standard lysis buffer $(50 \mathrm{mM}$ Tris $\mathrm{pH} 7.4,0.25 \mathrm{mM}$ sucrose and $5 \mathrm{mM}$ EDTA $\mathrm{pH} 8.0$, and a cocktail of protease inhibitors). Protein concentration was assayed by the method of Bradford (13), using BSA as working standard. Total protein extract $(10 \mu \mathrm{g})$ was loaded for each sample and analyzed using anti-MyoD (Santa Cruz Sc-760), anti-GLUT-4 (provided by Dr A. Zorzano) and anti$\alpha$-tubulin (Sigma T5168) antibodies. Total protein extract $(10 \mu \mathrm{g})$ were loaded for each sample. Specific proteins were detected with horseradish peroxidase (HRP)-conjugated secondary antibodies and a chemiluminescence kit. The sizes of proteins were estimated by using protein molecular-mass standards. Protein bands were quantified by scanning densitometry (Phoretix 1D International Ltd., UK).

Biochemicals. They were all reagent grade and obtained either from Roche S.A. (Barcelona, Spain) or from Sigma Chemical Co.
Statistical analysis. Statistical analysis of the data was performed by means of the Student's t-test.

\section{Results and Discussion}

Lewis lung carcinoma (LLC) implantation results in an important decrease in body weight $(15 \%)$ (Table I). This effect is accompanied by a significant decrease in the weights of EDL (31\%), tibialis (34\%), GSN (34\%) and soleus (17\%). While treatment with GW1929 had not effects on body weight or muscle weights in control animals, it resulted in a significantly increase in EDL weight in tumour-bearing animals. This increase was not observed in the rest of the muscles studied neither was an effect on body weight observed. Administration of the PPAR $\gamma$ agonist had not effect on tumour weight, suggesting that the transcription factor PPAR $\gamma$ is not involved in either the proliferation rate or apoptosis in this experimental tumour model.

The effects of GW1929 on GLUT-4 protein content are pictured in Fig. 1. While no effect was observed in control muscles, a clear significant effect of the agonist was observed in EDL muscles (21\%) in tumour-bearing mice. Interestingly this effect was not observed in the GSN muscle. It is well known that PPAR $\gamma$ is involved in glucose transport in skeletal muscle and that agonist of this transcription factor has been used for the treatment of hyperglycemia and diabetes (9), in general in pathological states where insulin resistance is observed. Insulin sensitivity is often decreased in cancer states (14); from this point of view, the results obtained are coherent and, surprisingly, only involve white skeletal muscle.

Fig. 2 shows the effects of the agonist on MyoD content in both EDL and GSN muscles. Again, no effect of the agonist 
EDL

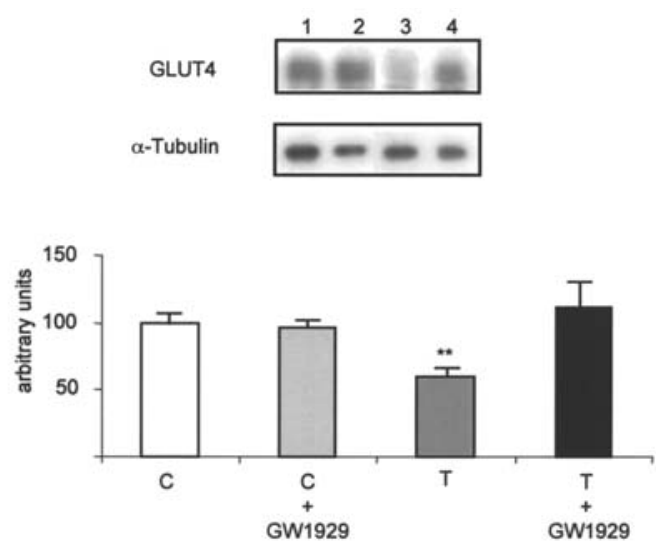

GSN

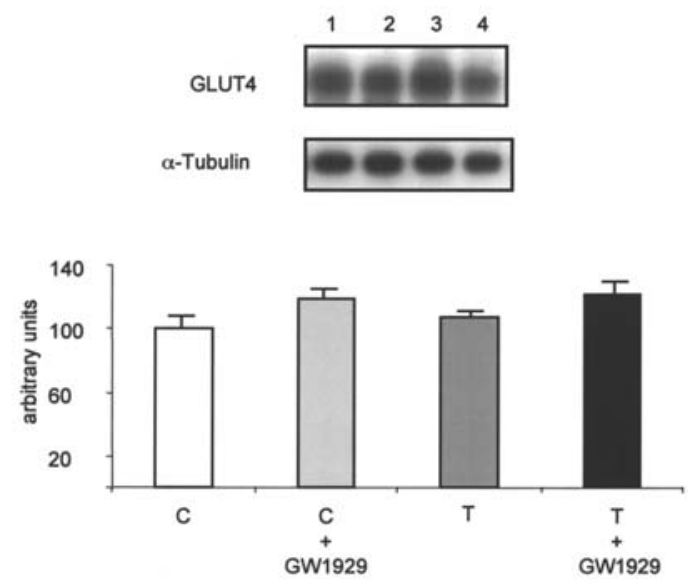

Figure 1. Effects of GW1929 on GLUT-4 protein content in skeletal muscle of tumour-bearing mice. For further details, see Materials and methods section. The data are expressed as a percentage of the control values. The results are mean values \pm SEM for a four animals. C, control; GW1929, treated animals; $\mathrm{T}$, tumour-bearing animals; EDL, extensor digitorum longus; GSN, gastrocnemius. 1, control; 2, GW1929-treated animals; 3, tumourbearing animals; 4, tumour-bearing animals treated with GW1929. Values that are significantly different by the Student's t-test from the non-tumourbearing animals groups are indicated by ${ }^{* *} \mathrm{p}<0.01$.

was observed in control animals but treatment with GW1929 resulted in an increase of $21 \%$ of the MyoD content in EDL muscle in tumour-bearing mice. This observation is of high interest since $\mathrm{MyoD}$ is a key transcription factor in skeletal muscle differentiation (15) and muscle wasting associated with cancer is linked with a decrease in its content, at least, in experimental animals (16).

The fact that the effects of the PPAR $\gamma$ agonist are observed in EDL is striking and seems to be very specific. We have found no satisfactory explanation for this observation; however, previous studies carried out in our laboratory showed that the use of hypolipidemic agents (which in a way behave as PPAR $\gamma$ agonists) resulted in different effects in red and mixed fiber muscles (17).

Taking into consideration the fact that, as we have previously and amply reported during experimental cancer cachexia, the main mechanism that it is activated and that is related with wasting is, indeed, muscle proteolysis $(4,5,18)$, we decided to investigate if the proteolytic rate was affected or not in the tumour-bearing rats. We incubated isolated skeletal muscles in an ex vivo set up as previously described
EDL

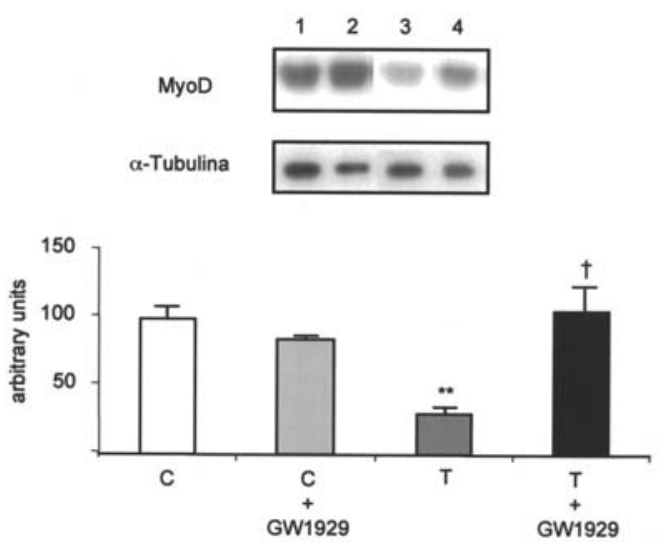

GSN

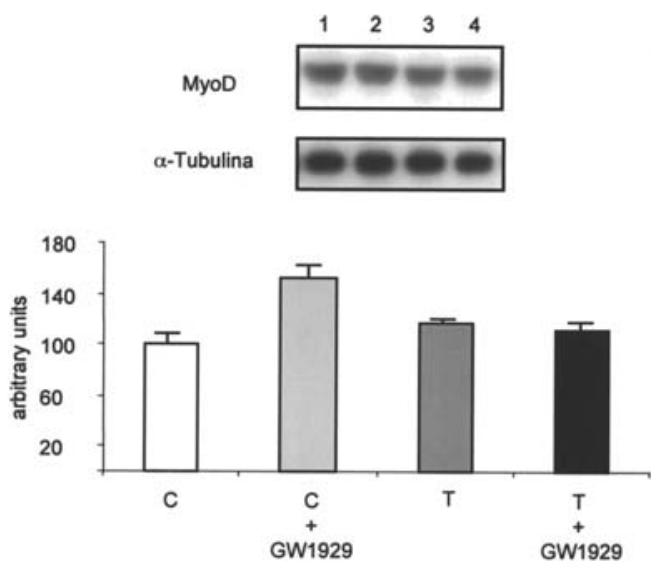

Figure 2. Effects of GW1929 on MyoD protein content in skeletal muscle of tumour-bearing mice. For further details, see Materials and methods section. The data are expressed as a percentage of the control values. The results are mean values \pm SEM for a four animals. C, control; GW1929, treated animals; T, tumour-bearing animals; EDL, extensor digitorum longus; GSN, gastrocnemius. 1, control; 2, GW1929-treated animals; 3, tumour-bearing animals; 4, tumour-bearing animals treated with GW1929. Values that are significantly different by the Student's t-test from the non-tumour-bearing animals groups are indicated by ${ }^{* *} \mathrm{p}<0.01$. Values that are significantly different by the Student's t-test from the non-treated animals are indicated by ${ }^{\dagger} \mathrm{p}<0.05$.

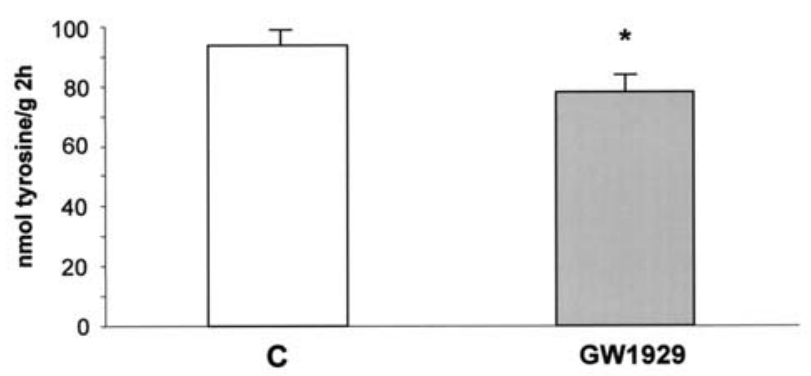

Figure 3. Effects of GW1929 on the proteolytic rate in EDL muscles. For further details, see Materials and methods section. The data are expressed as $\mathrm{nmol}$ tyrosine $/ \mathrm{g} / 2 \mathrm{~h}$. The results are mean values $\pm \mathrm{SEM}$ for a eight number of animals. C, control; GW1929, treated muscles; EDL, extensor digitorum longus. Values that are significantly different by the Student's t-test from the non-treated muscles are indicated by ${ }^{*} \mathrm{p}<0.05$.

(11) and examined the proteolytic rates in the presence or absence of the inhibitor. The results presented in Fig. 3 clearly show that the GW1929 agonist significantly reduces the proteolytic rate in incubated muscles $(17 \%)$. These results 
seem to indicate that an activation of PPAR $\gamma$ may be involved in the proteolytic events that take place in skeletal muscle during cancer cachexia.

Collectively, the results presented clearly indicate that the effects of the PPAR $\gamma$ agonist in muscle wasting deserves further investigation devoted to a better under-standing of the role of PPARs in skeletal muscle metabolism since they may serve as the basis for the development of new strategies for treating cachexia in many types of diseases such as cancer or infection.

\section{Acknowledgements}

This study was supported by grants from the Instituto de Salud Carlos III (03/0100) of the Ministerio de Sanidad y Consumo, from the Dirección General de Investigación Científica y Técnica (SAF4744-2005) of the Ministerio de Educación y Ciencia, from the Generalitat de Catalunya (SGR/00108), from Ministerio de Ciencia y Tecnologia (VIN03/021), and by grant SAF-2003-04223 from the Ministerio de Ciencia y Tecnología (MCyT).

\section{References}

1. Argiles JM, Alvarez B and López-Soriano FJ: The metabolic basis of cancer cachexia. Med Res Rev 17: 477-498, 1997.

2. Warren S: The immediate causes of death in cancer. Am J Med Sci 184: 610-615, 1932.

3. Argiles JM, Busquets S, Felipe A and López-Soriano FJ: Molecular mechanisms involved in muscle wasting in cancer and ageing: cachexia versus sarcopenia. Int J Biochem Cell Biol 37: 1084-1104, 2005.

4. Llovera M, García-Martínez C, Agell N, López-Soriano FJ and Argilés JM: Muscle wasting associated with cachexia is linked to an important activation of the ATP-dependent ubiquitinmediated proteolysis. Int J Cancer 61: 138-141, 1995.

5. García-Martínez C, Agell N, Marzábal M, López-Soriano FJ and Argilés JM: Ubiquitin gene expression is increased in skeletal muscle of tumour-bearing rats. FEBS Lett 338: 311-318, 1994.
6. Van Royen M, Carbó N, Busquets S, Alvarez B, Quinn LS, López-Soriano FJ and Argilés JM: DNA fragmentation occurs in skeletal muscle during tumor growth: a link with cancer cachexia? Biochem Biophys Res Commun 270: 533-537, 2000.

7. Sanchís D, Busquets S, Alvarez B, Ricquier D, López-Soriano FJ and Argilés JM: Skeletal muscle UCP2 and UCP3 gene expression in a rat cancer cachexia model. FEBS Lett 436 : 415-418, 1998.

8. Berger $\mathbf{J}$ and Moller DE: The mechanisms of action of PPARs. Annu Rev Med 53: 409-435, 2002.

9. Ferre P: The biology of peroxisome proliferator-activated receptors: relationship with lipid metabolism and insulin sensitivity. Diabetes 53: S43-S50, 2004.

10. Lopez-Soriano J, Chiellini C, Maffei M, Grimald PA, Argiles JM: Roles of skeletal muscle and peroxisome proliferator-activated receptors in the development and treatment of obesity. Endocr Rev 27: 318-329, 2006.

11. Busquets S, Alvarez B, López-Soriano FJ and Argilés JM: Branched-chain amino acids: a role in skeletal muscle proteolysis in catabolic states? J Cell Physiol 191: 283-289, 2002.

12. Waalkes TP and Udenfriend S: A fluorometric method for the estimation of tyrosine in plasma and tissues. J Lab Clin Med 50: 733-736, 1957.

13. Bradford MM: A rapid and sensitive method for the quantitation of microgram quantities of protein utilizing the principle of protein-dye binding. Anal Biochem 72: 248-254, 1976.

14. Argilés JM and López-Soriano FJ: Insulin and cancer. Int J Oncol 18: 1932: 683-687, 2001.

15. Naya FS and Olson E: MEF2: a transcriptional target for signaling pathways controlling skeletal muscle growth and differentiation. Curr Opin Cell Biol 11: 683-688, 1999.

16. Costelli P, Muscaritoli M, Bossola M, Moore-Carrasco R, Crepaldi S, Grieco, Autelli R, Bonelli G, Pacelli F, LopezSoriano FJ, Argiles JM, Doglietto GB, Baccino FM and Rossi-Fanelli F: Skeletal muscle wasting in tumor-bearing rats is associated with MyoD down-regulation. Int J Oncol 26: 1663-1668, 2005.

17. Busquets S, Carbó N, Almendro V, Figueras M, LópezSoriano FJ and Argilés JM: Hyperlipemia: a role in regulating UCP3 gene expression in skeletal muscle during cancer cachexia? FEBS Lett 505: 255-258, 2001.

18. Costelli P, Tullio RD, Baccino FM and Melloni E: Activation of $\mathrm{Ca}(2+)$-dependent proteolysis in skeletal muscle and heart in cancer cachexia. Br J Cancer 84: 946-950, 2001. 